\title{
O BIBLIOTECÁRIO ATUANTE EM BIBLIOTECAS UNIVERSITÁRIAS NO SÉCULO XXI: A NECESSIDADE DE ADEQUAÇÃO AO MODERNO PROFISSIONAL DA INFORMAÇÃO (MIP)
}

\author{
THE ACTING LIBRARIAN AT UNIVERSITY LIBRARIES IN THE XXI CENTURY: \\ THE NEED TO ADAPT TO THE MODERN INFORMATION PROFESSIONAL (MIP)
}

\author{
Jorge Santa Annal \\ Maria Aparecida de Mesquita Calmon ${ }^{2}$
}

\begin{abstract}
RESUMO
A diversidade na oferta de serviços e produtos constitui uma das características mais marcantes das bibliotecas universitárias (BU). Essa diversidade se amplia constantemente, sobretudo com a crescente utilização das novas tecnologias e o acúmulo de informações geradas, o que fez desencadear a necessidade de ampliação das competências e características dos profissionais que atuam nessas unidades de informação. A fim de acompanhar essas mudanças, os bibliotecários precisam adquirir novas competências, adequando-se ao perfil de um profissional inovador, categorizado como Moderno Profissional da Informação (MIP). Assim sendo, este estudo objetiva apresentar as características e competências dos bibliotecários atuantes em BU, relacionando-as ao perfil do MIP. Para tanto, o artigo discute, com base na literatura, o contexto no qual se situam as BUs, bem como as principais atividades prestadas, e as competências necessárias para que os bibliotecários sejam considerados MIP. Por fim, foi realizado um estudo em uma BU, aplicando questionário a 15 bibliotecários com vistas a investigar suas competências. Após análise e comparação entre as competências desses sujeitos com as do MIP, conclui-se que as competências do MIP são praticadas pelos bibliotecários que atuam em BU, sendo necessário, a priori, o investimento na formação continuada. Essa formação é praticada pelos profissionais de diferentes formas, sendo também viabilizada pela unidade de informação, cabendo ao próprio profissional divulgar essa necessidade e desejo constante de aprimoramento, com vistas a consolidar a melhoria contínua dos serviços prestados nessas unidades de informação.
\end{abstract}

PALAVRAS-CHAVE: Biblioteca universitária. Tecnologia da informação. Explosão informacional. Bibliotecário. Competência profissional.

\begin{abstract}
The diversity in the provision of services and products is one of the most striking features of the university libraries (BU). This diversity expands constantly, especially with the increasing use of new technologies and the accumulation of information generated, what did trigger the need to expand the skills and characteristics of professionals working in these units of information. To accompany these changes, librarians need to acquire new skills, adapting to an innovative professional, categorized as Modern Information Professional ( MIP ) profile. Therefore, this study aims to present the characteristics and skills of librarians active in BU, relating them to the MIP profile. To this end, the article discusses, based on the literature, the context in which are located the BUs as well as the main activities provided, and the skills necessary for librarians to be considered MIP. Finally, a study was conducted in a BU A questionnaire was administered to 15 librarians in order to investigate their skills. After analyzing and comparing the knowledge of these subjects with the MIP, it is concluded that the MIP skills are practiced by librarians who work at BU, being necessary a priori investment in continuing education. This training is practiced by professionals in different ways, and also made possible by
\end{abstract}

1 Graduado em Biblioteconomia pela Universidade Federal do Espírito Santo (UFES). Professor de Departamento de Biblioteconomia da UFES. Pesquisador atuante no ramo da Consultoria Informacional e Normalização de Trabalhos Científicos. E-mail: jorjao20@yahoo.com.br

2 Graduanda em Biblioteconomia pela Universidade Federal do Espírito Santo (UFES). E-mail: mariaaparecida@yahoo.com

Enviado em: 08/01/2015 - Aceito em: 06/05/2015 
the information unit, health professionals should promote itself this need and desire for constant improvement, with a view to consolidating the continuous improvement of services in these units of information.

KEYWORDS: University library. Information technology. Information explosion. Librarian. Professional competence.

\section{INTRODUÇÃO}

As unidades de informação, semelhantemente às demais organizações existentes na sociedade contemporânea, estão inseridas em um contexto dinâmico e diversificado, devendo reformular regularmente seus paradigmas, tendo em vista adequarem-se às novas necessidades demandadas pelos usuários que usufruem dos serviços e produtos por elas oferecidos.

As bibliotecas universitárias (BUs) inserem-se nesse contexto com maior intensidade. Isso devido à diversidade de produtos e serviços que devem ser oferecidos à comunidade servida, a universidade, devendo viabilizar subsídios que sustentem a tríade dessas instituições acadêmicas: ofertar atividades de pesquisa, de ensino e de extensão.

As atividades biblioteconômicas realizadas nessas modalidades de bibliotecas não devem restringir, tão somente, a fazeres técnicos, mas devem convergir a um somatório de serviços, que tendam a satisfazer integralmente as propostas da universidade, oferecendo suporte "[...] ao ensino, à pesquisa e à extensão, de forma que os serviços de informação da Biblioteca atendam a todos os usuários, sem distinção" (BEM et al., 2013, p. 76, grifo nosso).

A dinâmica que envolve as BUs exige sua interação com outras unidades de informação de forma sistêmica, tornando-as um organismo integrado, objetivando satisfazer exigentes demandas. Desse modo, o paradigma emergente é o da socialização, devendo a BU se reinventar a cada dia, a fim de se manter com o espaço privilegiado para a produção e disseminação do conhecimento (CARVALHO, 2011).

A fim de alcançar esses propósitos, a BU utiliza das novas tecnologias da informação e comunicação (TICs) a fim de se tornarem atreladas a outras unidades, rompendo-se as limitações de tempo e de espaço. Com a adesão das novas tecnologias, as bibliotecas caminham para a virtualização, onde seus produtos e serviços são disponibilizados em ambiente digital, mas sem desconsiderarem a oferta de produtos, também, em ambiente físico, adequando-se a um ambiente cada dia mais misto ou híbrido.

O estudo de Cunha (2010, p. 1) proclama com excelência a situação da BU diante da oferta híbrida de seus produtos e serviços. Segundo esse autor, a biblioteca se encontra na atualidade, em um momento de encruzilhada, disponibilizando suas atividades tanto em ambiente digital quanto impresso, por conseguinte, esse contexto plural pode representar inúmeros desafios para os profissionais que não estão habilitados a atuar em meio a essa diversidade. A BU está permeada por “[...] desafios complexos que exigem muita atenção por 
parte dos gestores das bibliotecas para poderem atravessar uma verdadeira encruzilhada [...]", fato esse que exige a adequação profissional, por meio da aquisição de novas competências.

No que se refere ao perfil dos profissionais que atuam nesses ambientes híbridos, inúmeros estudos surgem a respeito da postura do profissional bibliotecário, com o intento de demonstrar quais as competências e habilidades necessárias para que o bibliotecário gerencie com efetividade as unidades e serviços de informação. Analisando a literatura sobre o assunto, identifica-se que um dos estudos mais abrangentes a respeito das competências do profissional da informação ${ }^{3}$ diz respeito às pesquisas realizadas sobre o Moderno Profissional da Informação (MIP).

A gênese dessa terminologia permeia a década de 90, a partir dos estudos financiados pela extinta Federação Internacional de Bibliotecários (FID), no ano de 1992, sendo aperfeiçoada, logo em seguida, com as pesquisas de Ponjuan Dante (2000). Diversos outros estudos foram realizados ao longo das décadas seguintes que discutiam as novas competências, atribuições e habilidades do MIP, incluindo-se, especificamente nesses estudos, o profissional bibliotecário. Citam-se alguns estudos brasileiros: Smit (2000), Valentim (2000), Marchiori (1996), Tarapanoff (1997), Guimarães (1997), dentre outros.

O ponto inicial dessas discussões é evidenciado a partir do IV Encontro de Diretores das Escolas de Biblioteconomia e Ciência da Informação do Mercosul, realizado no ano de 2000, em Montevidéu, momento em que foram determinadas as seguintes competências para que os bibliotecários atingissem o status de MIP: competências de comunicação e expressão, técnico científica, gerenciais, sociais e políticas.

Percorridos mais de 20 anos após a formulação das competências do MIP e diante do momento de encruzilhada e da diversidade de atividades prestadas pela BU, permeada por um contexto em ebulição, este estudo objetiva apresentar as características dos bibliotecários atuantes em BU relacionando-as ao perfil do MIP. Para tanto, o estudo será sustentado pelos seguintes objetivos de natureza específica: discutir, com base na literatura, o contexto no qual se situam as BUs; apresentar as principais atividades prestadas pelas BUs e demonstrar as competências necessárias para que os bibliotecários atuantes nessas bibliotecas sejam considerados MIP.

Além do estudo teórico, recorreu-se à pesquisa de Santa Anna, Pereira e Calmon (2013), quando concluíram haver a necessidade do bibliotecário se tornar MIP em meio às transformações, tendo que se adaptar para não ser marginalizado, o que exige uma postura pró-ativa, criativa e ousada, ampliando suas competências. A referida pesquisa recomendou, após análise bibliográfica, a aplicação do estudo em uma unidade híbrida, visando investigar essas inquietudes no âmbito real.

\footnotetext{
${ }^{3}$ Diz respeito aos profissionais que lidam com a informação, incluindo-se os profissionais que formam as "três Marias", quais sejam: os bibliotecários, museólogos e arquivistas (SMIT, 2000). Contudo, segundo a CBO (apud MILANO; DAVOC, 2009), os bibliotecários são considerados profissionais da informação por excelência. Assim, no contexto desta pesquisa, consideraram-se como profissionais da informação, apenas os bibliotecários.
} 
Sendo assim, elaborou-se esta pesquisa ${ }^{4}$, aplicando, metodologicamente, um questionário a 15 bibliotecários atuantes em uma BU, com vistas a investigar suas competências. O questionário foi construído com perguntas fechadas, tendo como base para sua construção, as quatro competências do MIP propostas no encontro realizado em nível de Mercosul. Após a coleta, os dados foram interpretados à luz dessas competências, refletindo comparativamente, o perfil dos bibliotecários investigados com o perfil do MIP.

\section{DESAFIOS DA BU E A NECESSIDADE DE ADEQUAÇÃO DO BIBLIOTECÁRIO AO MIP: O QUE DISPÕE A LITERATURA}

As mudanças surgidas no contexto da sociedade atual definem a formação de novas tendências a serem seguidas pelos indivíduos de uma nação. Essas inovações refletem no posicionamento das organizações, na tentativa de satisfazer as necessidades de seus públicos. No âmbito das unidades de informação, essa necessidade de adequação também tem sido uma realidade inquestionável.

Diferentemente do passado, as bibliotecas migraram de um paradigma voltado exclusivamente para o acervo, preocupando-se com a custódia documental, para uma nova preocupação, direcionada aos usuários da informação. Assim, as bibliotecas foram se desenvolvendo ao longo dos tempos, "[...] desfalecendo-se na atualidade como um espaço em prol de satisfazer as necessidades e exigências demandadas por seus usuários, migrando-se do paradigma da posse/guarda para o acesso [...]” (SANTA ANNA, 2013, p. 5).

As BUs inserem-se nessa mesma trajetória evolutiva, adquirindo "[...] múltiplas funções e uma série de procedimentos, produtos e serviços que foram desenvolvidos ao longo de décadas [...]" (CUNHA, 2010, p. 3). Todavia, segundo o mesmo autor, mesmo sofrendo alterações em sua estrutura e na forma de gerenciar e disponibilizar a informação, seu propósito vem sendo o mesmo, qual seja: “[...] proporcionar acesso ao conhecimento. Esse acesso ao conhecimento é que irá permitir que o estudante, o professor e o pesquisador possam realizar suas aprendizagens ao longo da vida".

Além de viabilizar o acesso informacional, as BUs realizam uma série de serviços, cujos objetivos, de modo geral, se direcionam à prestação de serviços a todos os personagens existentes na universidade, como os docentes, discentes, pesquisadores e técnicoadministrativos, oferecendo material informacional de acordo com as demandas dos conteúdos programáticos ou em projetos acadêmicos dos cursos ministrados pela universidade na qual encontram-se inseridas (MIRANDA, 2007).

No entanto, é importante destacar que os serviços biblioteconômicos realizados nas BUs somente serão ofertados com qualidade, à medida que a unidade informacional estabelecer, além das técnicas de organização e disponibilização da informação, a gestão e o

\footnotetext{
4 Alguns resultados preliminares desta pesquisa foram apresentados no XVIII Seminário Nacional de Bibliotecas Universitárias, ocorrido em 2014, na cidade de Belo Horizonte (MG).
} 
planejamento de suas atividades, buscando a melhoria contínua dos processos de trabalho. A esse respeito discursa Lubisco (2011, p. 19, grifos nosso) que “[...] a biblioteca universitária deve dispor de um instrumento que não só revele com fidedignidade seus status dentro da instituição (avaliação diagnóstica), mas que subsidie suas atividades de planejamento e gestão (avaliação corretiva)".

A chegada de um novo milênio, sustentado pelo avanço tecnológico proporcionou às universidades e suas bibliotecas ampliarem a oferta de produtos e serviços em diferentes formatos e ambientes, podendo disponibilizar seus recursos, também, no ambiente web. Assim,

O contexto que se apresenta é propício para mudar a natureza do empreendimento acadêmico. No caso da biblioteca universitária, é necessário examinar as enormes possibilidades do futuro e entender que o desafio mais crítico será remover os obstáculos que a impedem de responder às necessidades de uma clientela em mudança, transformar os processos e estruturas administrativas que caducaram e questionar as premissas existentes (CUNHA, 2000, p. 88).

Nesse enfoque, faz-se necessário que as BUs rompam as velhas concepções adequando seus processos de trabalho conforme as exigências dos usuários, oferecendo produtos e serviços de natureza mista/diversificada, de modo que o acesso seja ampliado, disponibilizado em diferentes formatos, podendo o usuário escolher uma opção que melhor lhe atenda ao solicitar um serviço de informação.

A oferta de produtos e serviços biblioteconômicos em ambiente digital não proporciona a extinção do espaço físico da biblioteca e os serviços presenciais oferecidos, cabendo à unidade prestar serviços de informação em diferentes formatos. Ao adquirir essa característica mista, essas unidades são consagradas com o que a literatura comumente denomina de Bibliotecas Híbridas. O que caracteriza esse novo espaço de trabalho é sua amplitude, de modo que são agregadas diferentes tecnologias, diferentes fontes, refletindo um novo estágio “[...] que hoje não é completamente digital, nem completamente impresso, utilizando tecnologias disponíveis para unir, em uma só biblioteca, o melhor dos dois mundos (o impresso e o digital)" (GARCEZ; RADOS, 2002, p. 47).

No entendimento de Tammaro e Saralleri (2008), nas bibliotecas híbridas projetam-se diferentes tecnologias, utilizando-se de sistemas integrados a fim de facilitar as atividades realizadas ao utilizar suportes variados, tanto em forma eletrônica quanto impressa. Ainda proferem os autores que a biblioteca híbrida se utiliza tanto de fontes informacionais eletrônicas quanto em papel. O foco do conceito de bibliotecas híbridas está nos serviços, que se adaptam ao novo contexto digital num esforço de transformação e reorganização da biblioteca tradicional.

Diante das pressões advindas da sociedade externa, do acúmulo informacional e do avanço das TICs, não resta dúvida de que as BUs entram em um ciclo de constantes inovações, tornando-se ambientes híbridos. Parafraseando Cunha (2010), espera-se que a 
biblioteca universitária do futuro, e paralelamente o profissional que a sustenta, não será extinto, mas deverá sofrer alterações, com base nas novas necessidades demandadas no contexto da universidade; trata-se de adequar-se para não marginalizar-se, pois os profissionais poderão atuar em um ambiente diferente do tradicional, um espaço amplo, mutante e diversificado.

Santa Anna, Gerlin e Siqueira (2013) concordam com esse pensamento e destacam que no iniciar do século XXI, a biblioteca universitária e os produtos e serviços por ela gerados vêm sendo influenciados pelas novas tecnologias, o que condiciona ao surgimento de novos perfis de demanda, levando, consequentemente, ao aparecimento de novos produtos e serviços e despertando práticas profissionais diferenciadas e inovadoras.

Essas práticas profissionais não podem se limitar apenas às atividades técnicas desenvolvidas por um profissional. Para se concretizarem, conforme os desafios da BU híbrida, é necessário que o profissional da informação adquira novas e contínuas competências, comungadas a partir da soma de novos conhecimentos, experiências, habilidades e atribuições. Essa conjugação de características profissionais viabiliza a formação do Moderno Profissional da Informação (MIP). Essa nova categorização profissional somente acontece se o bibliotecário buscar "[...] um intenso processo de educação continuada" (CASTRO, 2000, p.9).

Assim, para ser um MIP, o bibliotecário atuante em BU deve sofrer uma metamorfose, transformando-se em um agente de mudanças, gerenciando todas as fases do ciclo informacional, tendo em vista, atender com excelência e máxima qualidade, os usuários da informação. Faz-se necessário a fusão de competências, atuando ele em diferentes ramos de mercado, com múltiplas tecnologias e em múltiplos contextos, intervindo na realidade de forma técnica, humanista, estratégica e inovadora (SILVEIRA, 2008).

Conforme dispõe os estudos de Valentim (2000, p. 8), para o terceiro milênio, o bibliotecário deverá ser

[...] mais observador, empreendedor, atuante, flexível, dinâmico, ousado, integrador, proativo e principalmente mais voltado para o futuro. A formação, portanto, deve estar voltada para a obtenção de um profissional que atenda essas características (VALENTIM, 2000, p. 8),

sendo necessário para isso, adquirir diferentes competências, a ponto de conseguir realizar com efetividade os fazeres biblioteconômicos típicos das atuais BUs. As principais competências de um MIP são resumidas em quatro tipologias:

1 - competências de comunicação: diz respeito à interação que o profissional deve ter com seus usuários, com outras instituições e com as diversas tecnologias, facilitando o intercâmbio e compartilhamento de informações; logo, facilita a comunicação e o acesso informacionais (VALENTIM, 2000); 
2 - competências técnico-científicas: as competências técnico-científicas se referem ao trabalho realizado pelo bibliotecário em meio aos diversificados itens informacionais existentes no acervo. Aqui lhe cabem as funções, em sentido lato, de tratamento da informação (SANTA ANNA; PEREIRA; CAMPOS, 2013);

3 - competências gerenciais: refere-se àquelas voltadas para a gestão, abrangendo, holisticamente, as ações de "[...] Formular, dirigir, administrar, organizar e coordenar unidades, sistemas, projetos e serviços de informação [...]" (VALENTIM, 2000, p. 20);

4 - competências sociais e políticas: voltadas para as questões do ambiente externo, cabendo ao profissional, segundo Valentim (2000, p. 21), fomentar uma atitude "[...] aberta e interativa com os diversos atores sociais (políticos, empresários, educadores, trabalhadores e profissionais de outras áreas, instituições e cidadãos em geral) que configuram o atual ciclo informacional $[\ldots]$ "..

Após análises das reflexões propostas pela literatura a respeito das mudanças ocorridas nas BUs e a necessidade de aperfeiçoamento do bibliotecário atingindo um patamar de MIP, face aos novos desafios propostos nesses espaços de socialização, repleto pela diversidade de produtos e serviços, o próximo passo é investigar as competências do MIP em um contexto real, especificamente, os bibliotecários atuantes em unidade de informação de modalidade universitária.

\section{ANÁLISE DO PERFIL DOS BIBLIOTECÁRIOS ATUANTES EM BU: ESTUDO EM CAMPO}

$\mathrm{O}$ estudo in loco foi realizado em uma BU, tendo como sujeitos da pesquisa, 15 bibliotecários atuantes nesse espaço. A técnica de pesquisa utilizada para coleta de dados foi o questionário, contendo 17 questões fechadas, elaboradas com a finalidade de identificar os seguintes aspectos: o perfil da amostra estudada, as competências dos respondentes face às competências atribuídas ao MIP e as competências dos profissionais analisados na ambiência da unidade onde exercem as atividades bibliotecárias, a BU.

No que se refere aos aspectos relacionados ao perfil da amostra, perguntou-se o tempo de atuação dos profissionais em BUs. Os dados coletados demonstram que, 12 bibliotecários (80\% da amostra) atuam em BU há 5 anos ou mais; 2 respondentes (13,33\%) atuam há 1 ano e apenas 1 profissional respondeu que trabalha nesses tipos de bibliotecas há 2 anos (Gráfico $1)$. 


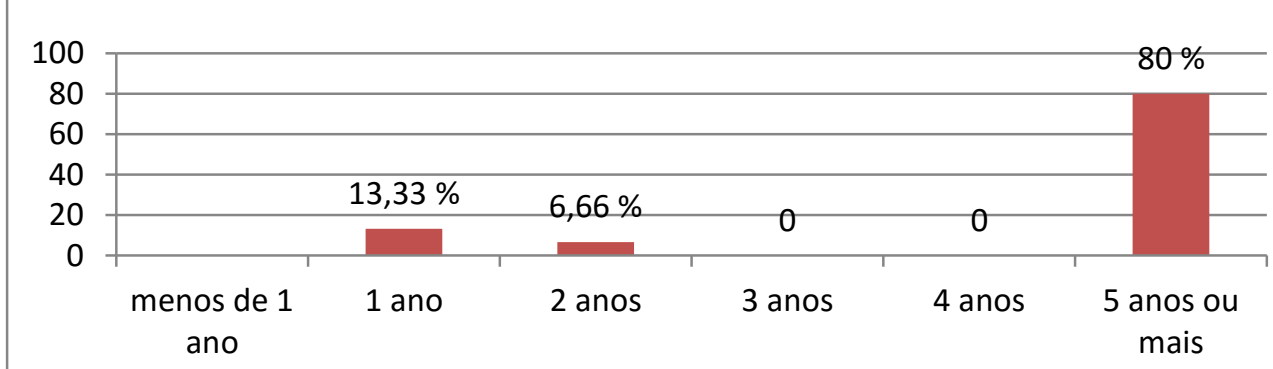

GRÁFICO 1 - Quanto tempo você atua em biblioteca universitária?

Fonte: dados da pesquisa

Com o objetivo de analisar a atuação dos profissionais em outros ambientes que não apenas a BU, a segunda pergunta indaga se eles, antes de atuar em BU, exerceram atividades em outras unidades ou espaços de informação. Para 6 pessoas (40\%) já atuaram em outras modalidades de bibliotecas. Já para 5 respondestes $(33,33 \%)$, atuaram em outros ambientes de informação e outras áreas da Biblioteconomia. Ao contrário, para 4 indivíduos (26,66\%), sempre exerceram a profissão em BU (Gráfico 2).

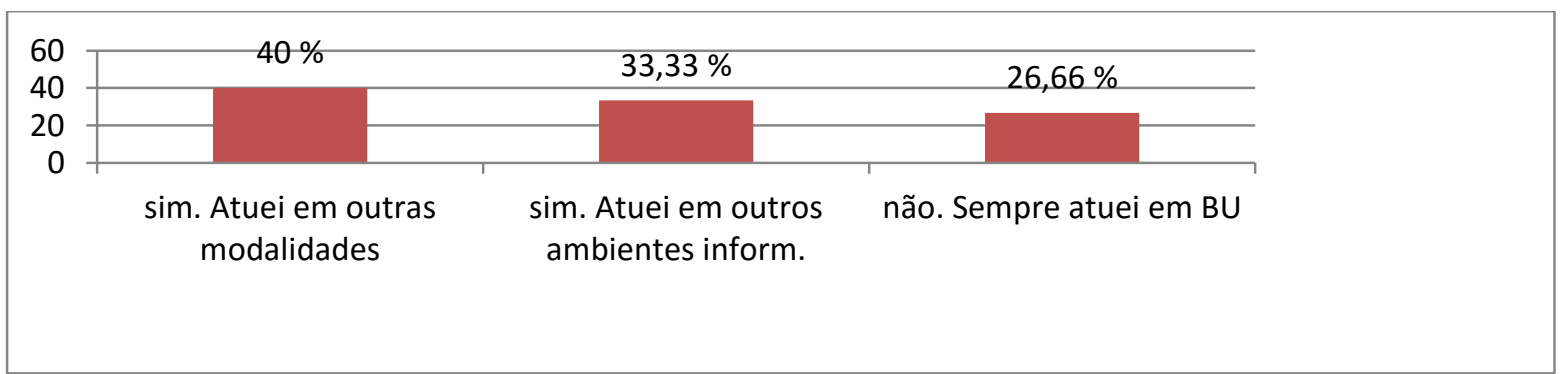

GRÁFICO 2 - Antes de atuar em BU, você atuou em outras unidades de informação?

Fonte: dados da pesquisa

O questionário investiga o motivo que levou os bibliotecários a atuarem em BU. Os dados tabulados expressam que, 5 pessoas $(33,33 \%)$ foram atuar em BU por considerar os serviços dessa modalidade mais abrangentes; de igual percentual, na visão de 5 pessoas $(33,33 \%)$, o motivo foi devido à interação que essa unidade possui com a academia; já 2 sujeitos $(13,33 \%)$ consideram que é devido à interação que essa unidade possui com a comunidade em geral; por fim, 3 respondentes (20\%) consideram a aprovação em concurso como principal motivo (Gráfico 3). 


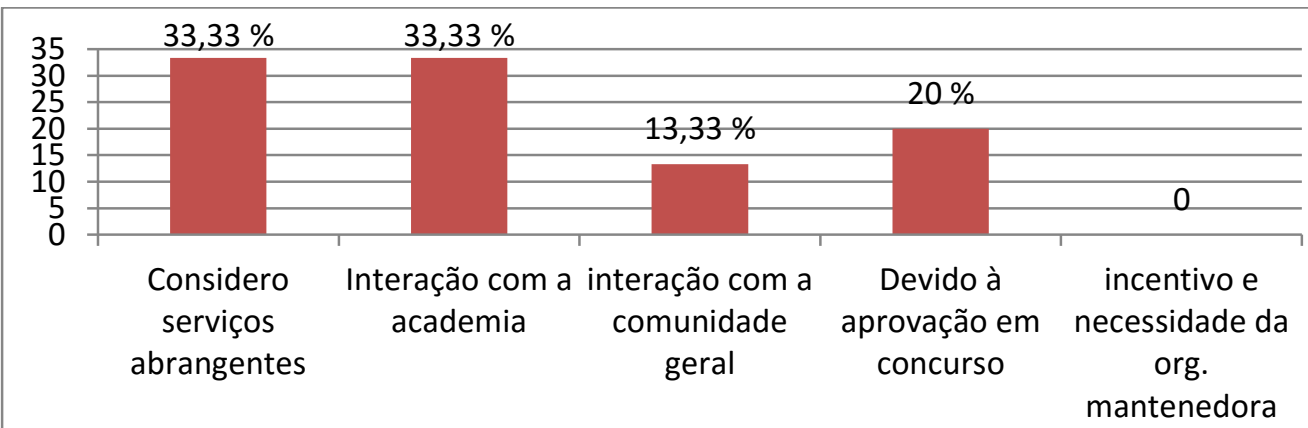

GRÁFICO 3 - O que te motivou a atuar em BU?

Fonte: dados da pesquisa

Visando conhecer a formação acadêmica e qualificação profissional do bibliotecário atuante na unidade analisada, a maioria, 13 sujeitos $(86,66 \%)$ possuem curso superior de Biblioteconomia e especialização; 1 bibliotecário $(6,66 \%)$ possui apenas o curso de Graduação em Biblioteconomia, e também 1 profissional $(6,66 \%)$ possui curso superior de Biblioteconomia e cursos extras de capacitação (gráfico 4).

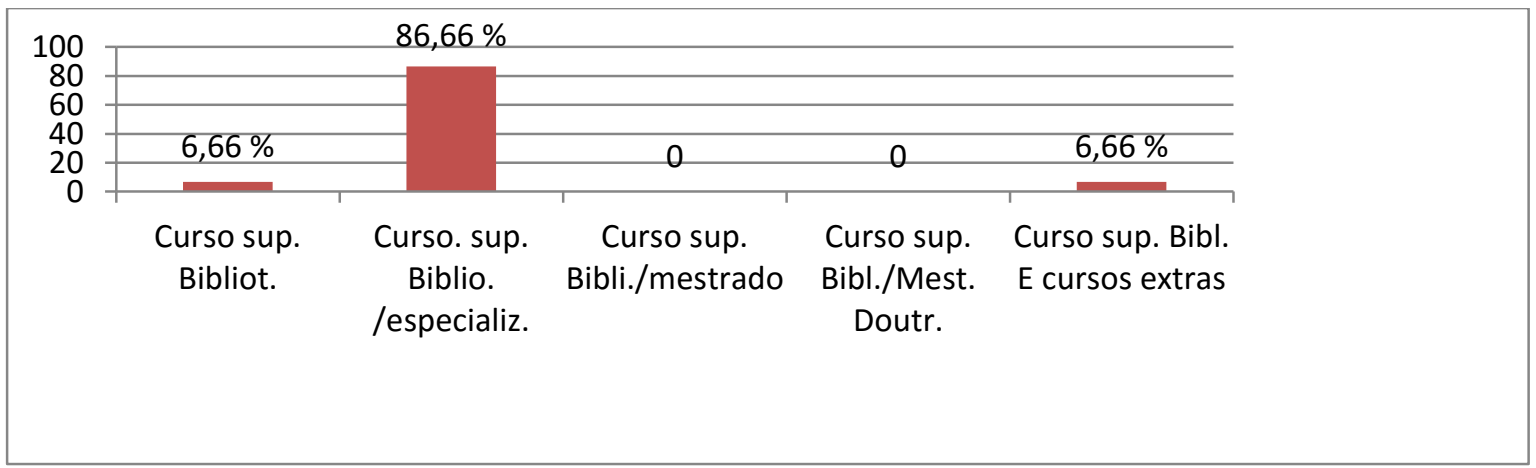

GRÁFICO 4 - Qual a sua formação acadêmica?

Fonte: dados da pesquisa

Após análise do perfil da amostra, o questionário investigou as competências pessoais/individuais dos profissionais. Foi perguntado, em um primeiro momento, se mesmo estando vinculado a uma unidade de informação específica (BU), o profissional possui capacidade de trabalhar em outras unidades e centros de informação, bem como em outros ramos de atuação bibliotecária (Gráfico 5).

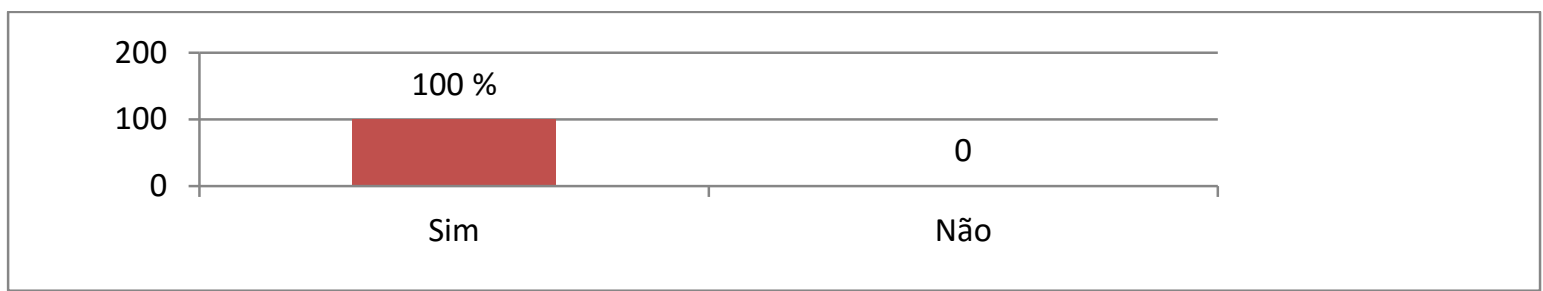

GRÁFICO 5 - Mesmo estando vinculado a uma unidade de informação específica (BU), você possui capacidade de trabalhar em outras unidades e centros de informação, bem como em outros ramos de atuação bibliotecária?

Fonte: dados da pesquisa 
Conforme informações expressas no gráfico acima, constata-se com louvor a ampliação das capacidades de atuação dos profissionais, não estando engessados apenas à BU, mas possuindo competências necessárias para exercer a profissão em outras unidades de informação e em outros ambientes de informação. Todos os respondentes (100\%) consideram-se capacitados para exercer atividades em outras ambiências.

Tendo em vista as capacidades profissionais elencadas na questão anterior, a pergunta seguinte analisa quais atividades específicas, desconsiderando-se o contexto da BU, o profissional está preparado a exercer. Ou seja, essa pergunta pretende investigar se os profissionais possuem as competências do MIP (Gráfico 6).

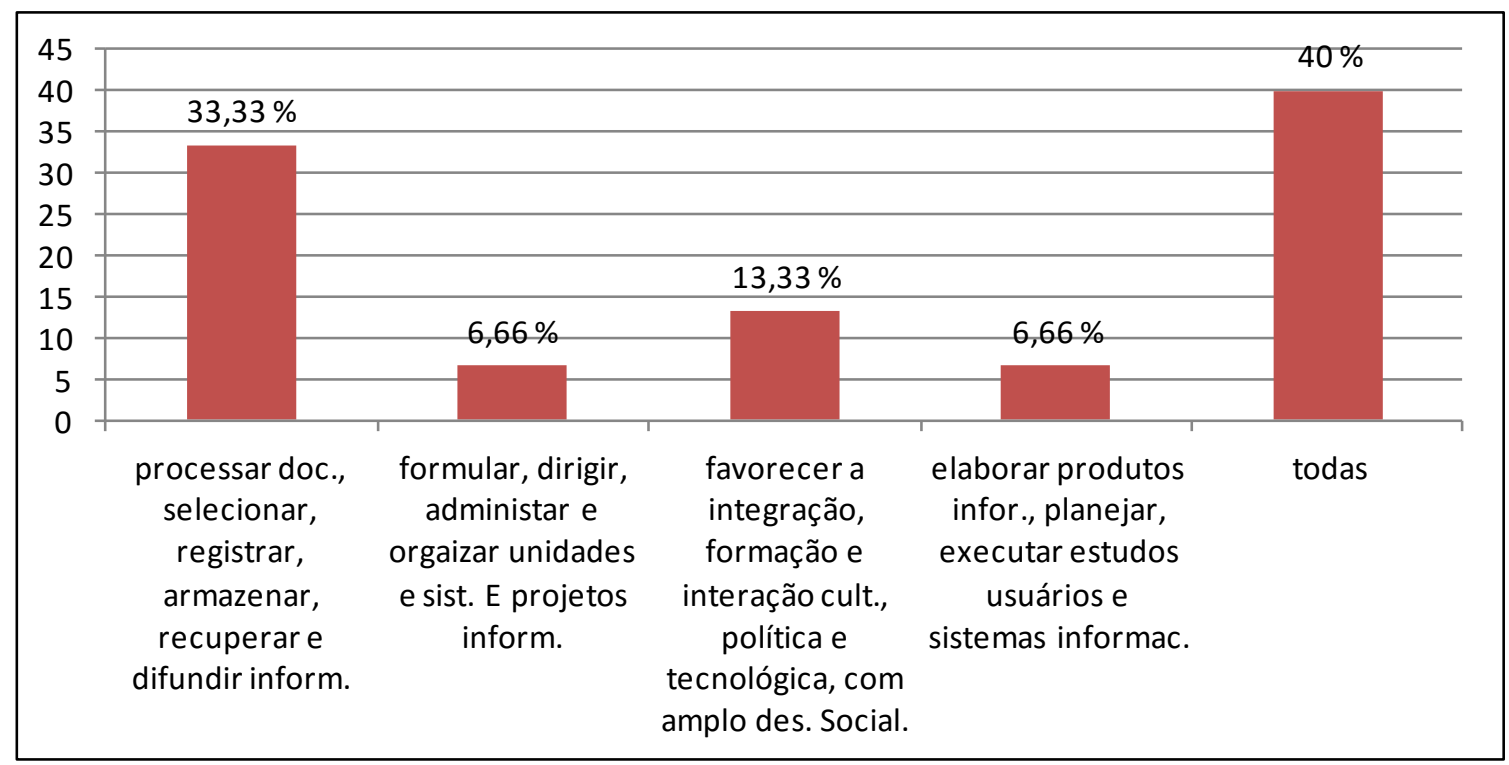

GRÁFICO 6 - Das atividades abaixo descritas, desconsiderando-se o contexto da BU, marque a que você considera capacitado a realizar:

Fonte: dados da pesquisa

Conforme ilustrado no gráfico, no entendimento de 5 respondentes $(33,33 \%)$ estão preparados a processar documentos, selecionar, registrar, armazenar, recuperar e difundir informação. Na visão de 1 pessoa $(6,66 \%)$, suas competências permeiam as atividade de formular, dirigir, administrar e organizar unidades, sistemas e projetos informacionais. Já 2 pessoas $(13,33 \%)$ são competentes a favorecer a integração, formação e interação cultural, política e tecnológica, com amplo desenvolvimento social. Para 1 pessoa $(6,66 \%)$, estão preparados a elaborar produtos informacionais, planejar, executar estudos de usuários e sistemas de informação. Por fim, a grande maioria, 6 pessoas (40\%) disseram possuir todas as competências descritas, ou seja, dos 15 sujeitos analisados, apenas 6 possuem as cinco competências que categorizam o bibliotecário como MIP.

É importante investigar se os profissionais, mesmo não possuindo as competências do MIP, reconhece a necessidade de adequação das competências profissionais face aos desafios dos novos tempos. Ao serem indagados sobre quais competências o profissional considera como necessárias ao fazer bibliotecário, de forma gloriosa, 14 pessoas $(93,33 \%)$ consideram 
todas elas como necessárias; porém, 1 indivíduo $(6,66 \%)$ considera os fazeres técnicocientíficos (Gráfico 7).

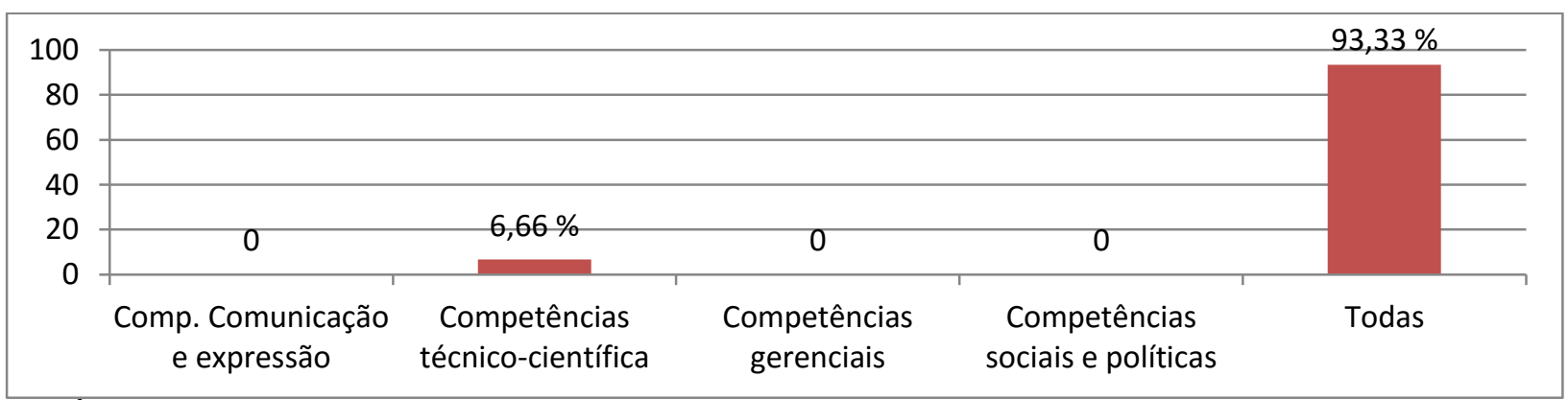

GRÁFICO 7 - Com as constantes inovações da sociedade moderna, qual das competências descritas, você considera necessária ao trabalho do bibliotecário moderno:

Fonte: dados da pesquisa

Não resta dúvida de que para adquirir todas as cinco competências do MIP é necessário que o profissional valorize a formação continuada. Quando investigados a respeito dessa formação, os resultados também são louváveis, pois, todos os respondentes (100\%) consideram como importante, o investimento na formação continuada (gráfico 8).

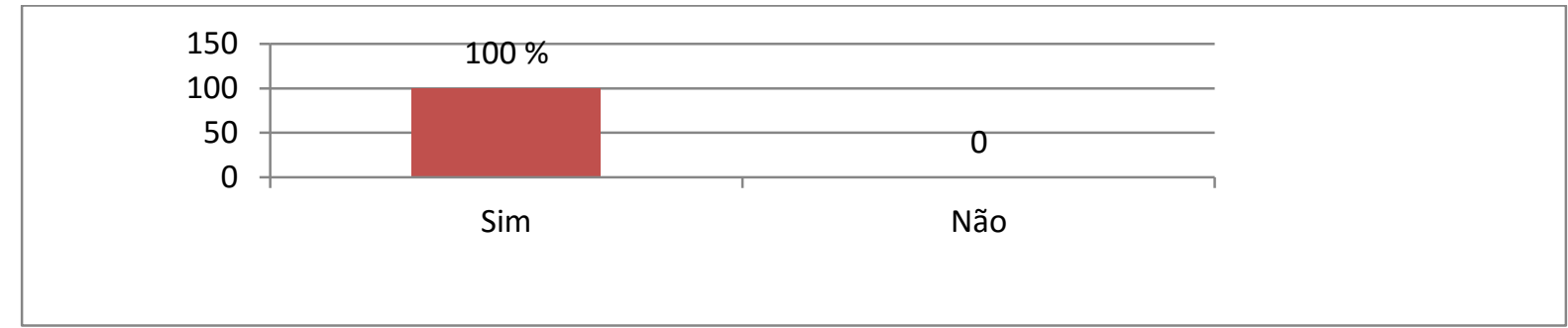

GRÁFICO 8 - Você considera importante a formação continuada do profissional?

Fonte: dados da pesquisa

Visando coletar dados a respeito do investimento na formação continuada, indagou-se de que forma o profissional mantém atualizada sua formação. De acordo com 3 sujeitos (20\%) investem na pós-graduação; também, na visão de outros 3 sujeitos (20\%), eles participam de minicursos de aperfeiçoamento quanto à prática bibliotecária. Já para 9 entrevistados (60\%), utilizam das três assertivas propostas na questão, ou seja, a formação continuada é consolidada por meio de cursos de pós-graduação, participação em minicursos de aperfeiçoamento quanto à prática bibliotecária, e realização de cursos extras de aperfeiçoamento em geral, como idiomas, oratória, etc. (Gráfico 9).

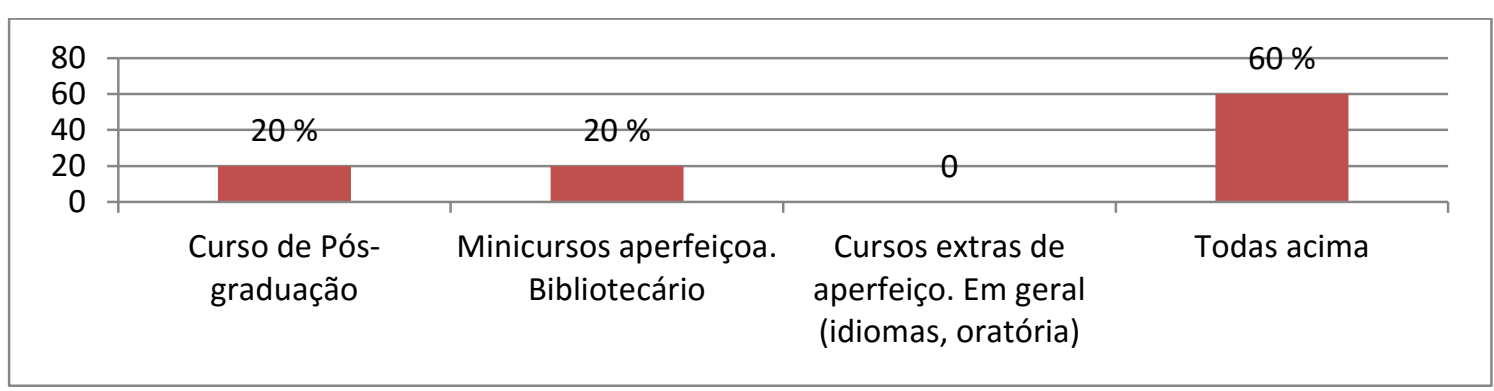

GRÁFICO 9 - Em caso positivo da questão anterior, como você gerencia a sua formação continuada?

Fonte: dados da pesquisa 
No que se refere ao uso das novas tecnologias, 2 profissionais $(13,33 \%)$ consideram necessária a realização de cursos para aperfeiçoamento, porém não participa; ao contrário, para a maioria, 13 participantes $(86,66 \%)$, acham necessária a realização de cursos para aperfeiçoamento e os realizam com frequência (Gráfico 10).

\begin{tabular}{|c|c|c|c|c|}
\hline \multirow{5}{*}{$\begin{array}{r}100 \\
80 \\
60 \\
40 \\
20 \\
0\end{array}$} & \multicolumn{4}{|c|}{$86,66 \%$} \\
\hline & & & & \\
\hline & $13,33 \%$ & & 0 & 0 \\
\hline & 7 & & & \\
\hline & $\begin{array}{l}\text { Acha necessário realizar } \\
\text { curos, mas não os faço }\end{array}$ & $\begin{array}{c}\text { Acho necessário a real. } \\
\text { De cursos e os realizo } \\
\text { frequent. }\end{array}$ & $\begin{array}{l}\text { Não acho necessário a } \\
\text { real. De cursos, já que } \\
\text { possuo conh. Suficiente }\end{array}$ & $\begin{array}{c}\text { Não uso as novas tecnol. } \\
\text { E não as considero como } \\
\text { válidas }\end{array}$ \\
\hline
\end{tabular}

GRÁFICO 10 - Quanto ao uso das novas tecnologias,

Fonte: dados da pesquisa

A última parte do questionário abarcou as competências dos profissionais no comparativo com o MIP, semelhante aos aspectos anteriores, no entanto, a análise se voltou para a atuação do profissional na ambiência da BU. Quando perguntados se existe um setor específico onde o profissional atua, todos os participantes disseram que atuam em um setor específico (Gráfico 11).

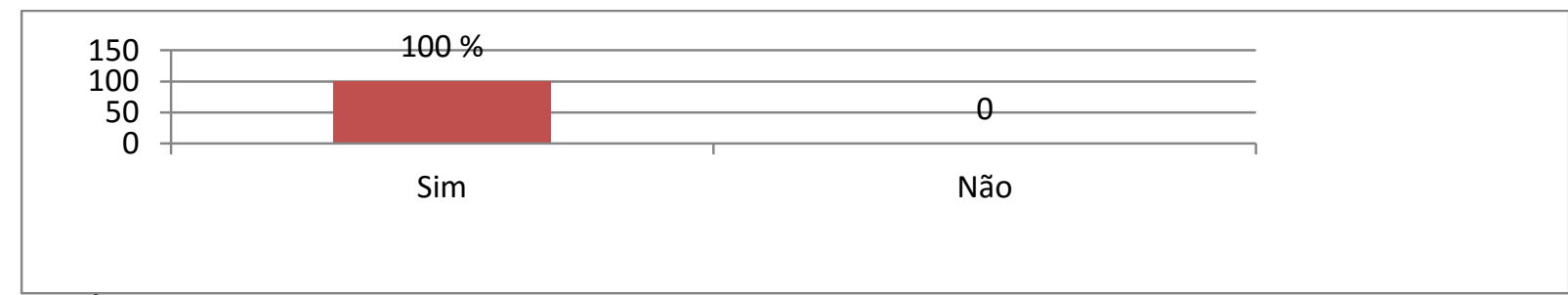

GRÁFICO 11 - Existe um setor específico onde você atua?

Fonte: dados da pesquisa

A maioria dos profissionais atuam no setor de processamento técnico (3 bibliotecários), direção (1), periódico (1) e 2 exercem atividades nos setores de referência e circulação.

Tendo em vista, verificar o contexto da BU e a flexibilidade do profissional em exercer todas as competências a ele atribuídas visando consolidar todas as suas capacidades, perguntou-se a respeito da atuação em outros setores (Gráfico 12). 


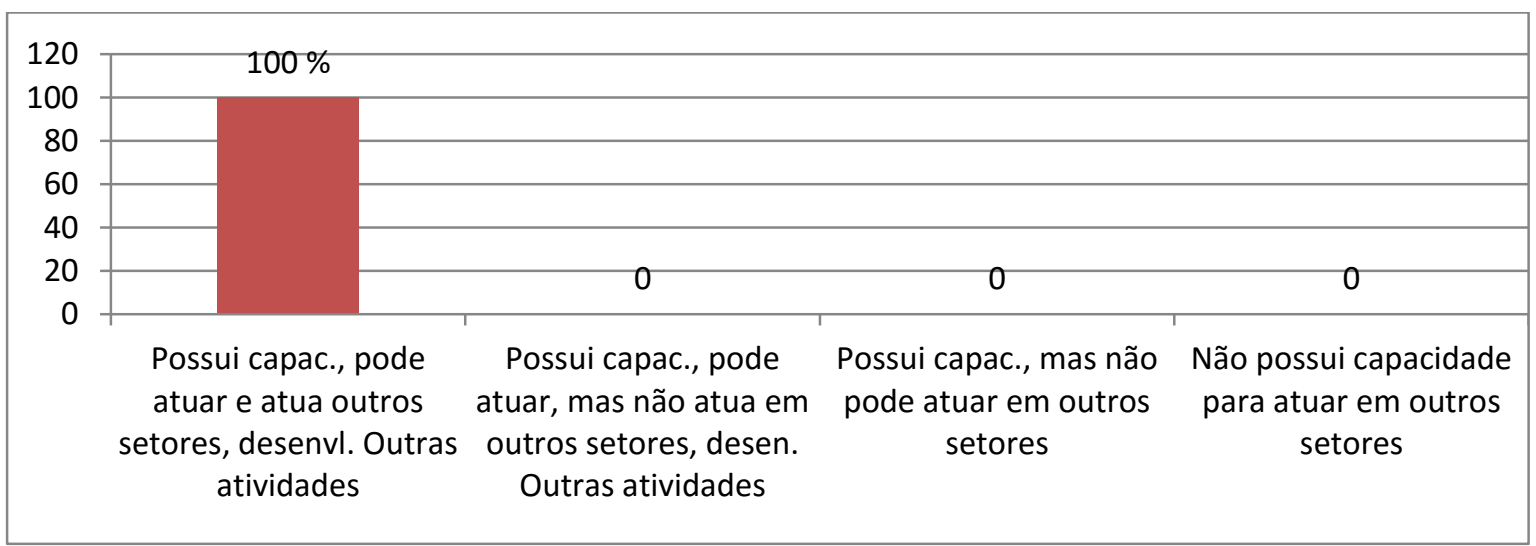

GRÁFICO 12 - Em caso afirmativo da questão anterior, mesmo atuando em um setor específico você Fonte: dados da pesquisa

Conforme consta no gráfico acima, percebe-se que todos os profissionais entrevistados (100\%) possuem capacidade, podem atuar e atuam em outros setores, desenvolvendo outras atividades, o que caracteriza a BU como um espaço flexível, permeado por trabalho em equipe, colaboração, reciprocidade e integração.

Tentando identificar as cinco competências do MIP voltadas para o contexto específico da BU, foram analisadas as atividades inerentes a cada uma das competências (Gráfico 13):

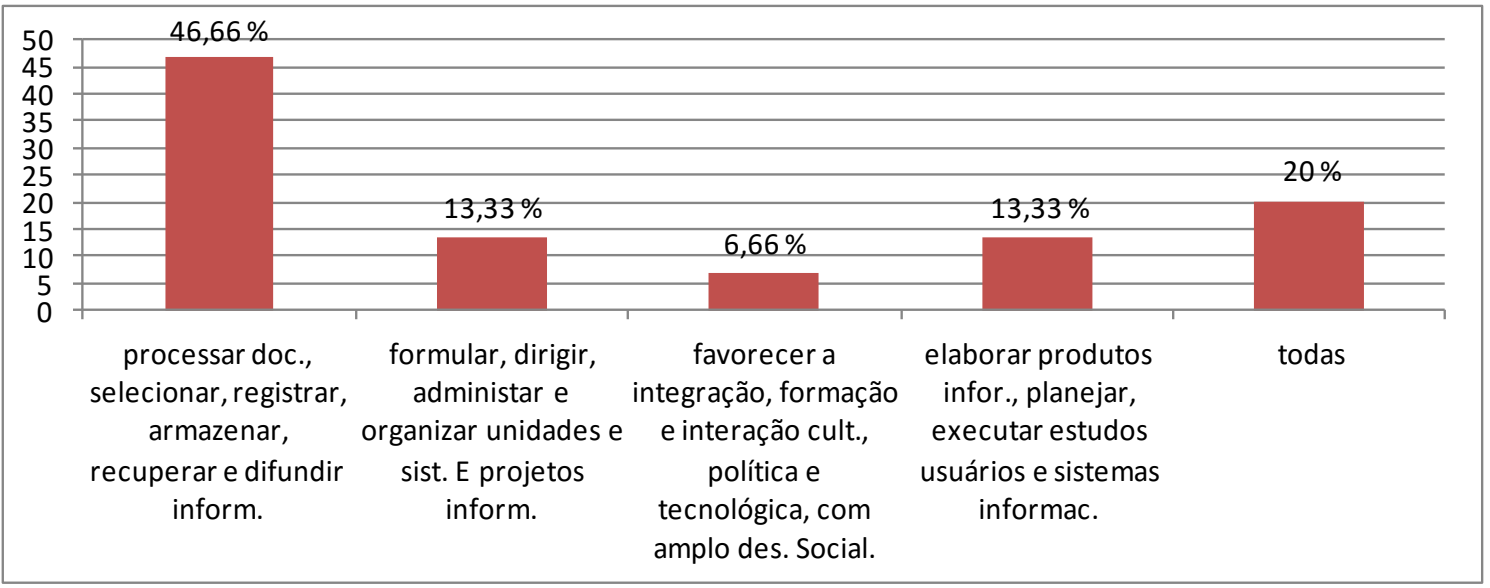

GRÁFICO 13 - Das atividades abaixo descritas, marque a que você mais realiza tendo em vista aquilo que a unidade de informação estabelece:

Fonte: dados da pesquisa

Assim, tentando identificar as cinco competências do MIP voltadas para o contexto específico da $\mathrm{BU}$, os dados obtidos nos informam que: 7 respondentes $(46,66 \%)$ processam documentos, selecionam, registram, armazenam, recuperam e difundem informação; 2 pessoas $(13,33 \%)$ formulam, dirigir, administram e organizam unidades, sistemas e projetos informacionais; 1 (6,66\%) favorece a integração, formação e interação cultural, política e tecnológica, com amplo desenvolvimento social; 2 sujeitos $(13,33 \%)$ elaboram produtos informacionais, planejam e executam estudos de usuários e sistemas informacionais; por fim, dos 15 bibliotecários, apenas 3 (20\%) realizam todas essas competências na BU. 
$\mathrm{Na}$ questão de número 14, pretendeu-se identificar as exigências da BU quanto à adequação do bibliotecário ao MIP. Desse modo, ao ser indagado a respeito do que a unidade recomenda no cotidiano do profissional, os dados confirmam que: para 1 profissional $(6,66 \%)$, para se realizar com efetividade o trabalho em BU, recomenda-se, principalmente a aquisição de competência de comunicação e expressão; no entendimento de 6 pessoas (40\%), é preciso obter principalmente competência técnico-científicas; a grande maioria, 8 indivíduos $(53,33 \%)$, considera que um trabalho em BU requer a aquisição de todas as competências listadas, quais são: comunicação, técnico-científica, gerenciais e sociais e políticas.

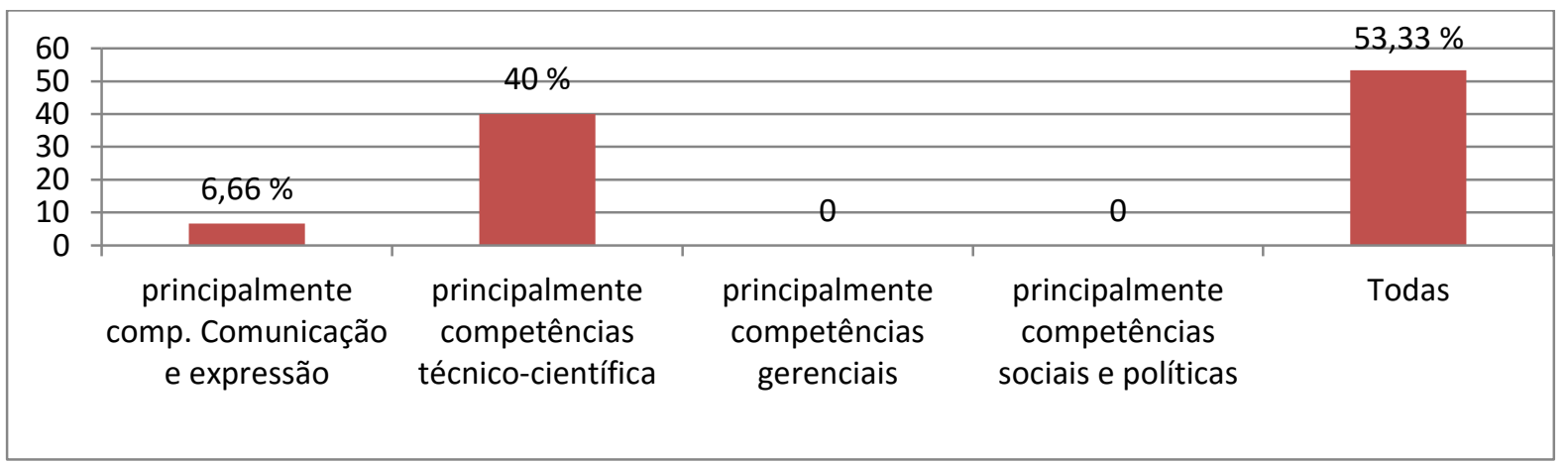

GRÁFICO 14 - Em seu trabalho cotidiano, a unidade de informação recomenda que você tenha

Fonte: dados da pesquisa

Quanto à formação continuada do profissional e o posicionamento da BU, obteve-se os seguintes dados: 2 sujeitos $(13,33 \%)$ destacaram que a BU incentiva a formação continuada; de forma gloriosa, mais da metade da amostra, 12 pessoas (80\%) consideram que a BU recomenda a formação continuada. No entanto, de forma contraditória, 1 sujeito aferiu que a unidade não se preocupa com a formação do profissional (Gráfico 15).

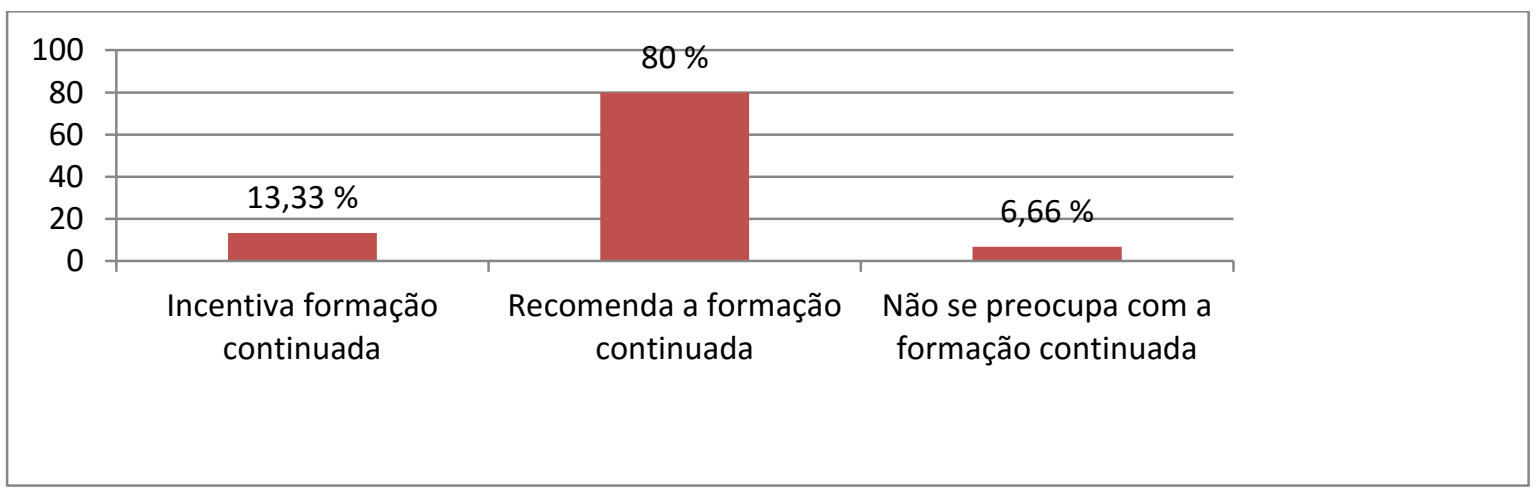

GRÁFICO 15 - No que diz respeito à sua formação continuada, a unidade

Fonte: dados da pesquisa

Ainda enfatizando o papel da formação continuada e valorização por parte da BU, a pergunta de número 16 indagou se há algum incentivo por parte da unidade aos profissionais quanto à formação continuada. Os dados obtidos nos permite descrever que a unidade incentiva essa formação, oferecendo melhores remunerações aos profissionais que se qualificam. De acordo com 1 bibliotecário $(6,66 \%)$, a BU não se preocupa com a formação 
continuada; também, 1 pessoa $(6,66 \%)$ considera que a formação continuada desperta promoções; já para 13 respondentes $(86,66 \%)$, a formação continuada proporciona ganhos financeiros (gráfico 16).

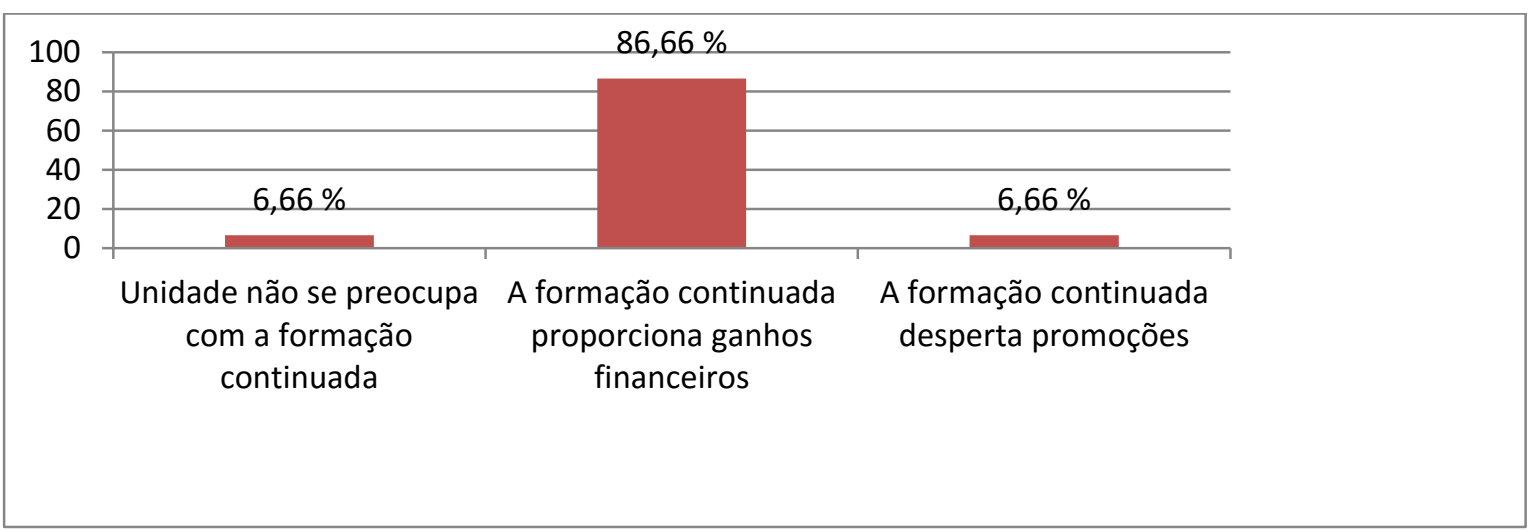

GRÁFICO 16 - Há algum incentivo por parte da unidade aos profissionais quanto à formação continuada? Fonte: dados da pesquisa

No contexto da BU na contemporaneidade não resta dúvida de que as grandes mudanças são fruto da inserção ao paradigma tecnológico. As novas tecnologias modificam os serviços biblioteconômicos, sendo necessária a constante adequação do profissional, tendo em vista ampliar seus fazeres, adequando-se às novas necessidades. Sendo assim, a última pergunta investiga o que a BU faz no intento de permitir a adequação profissional aos novos recursos utilizados (Gráfico 17):

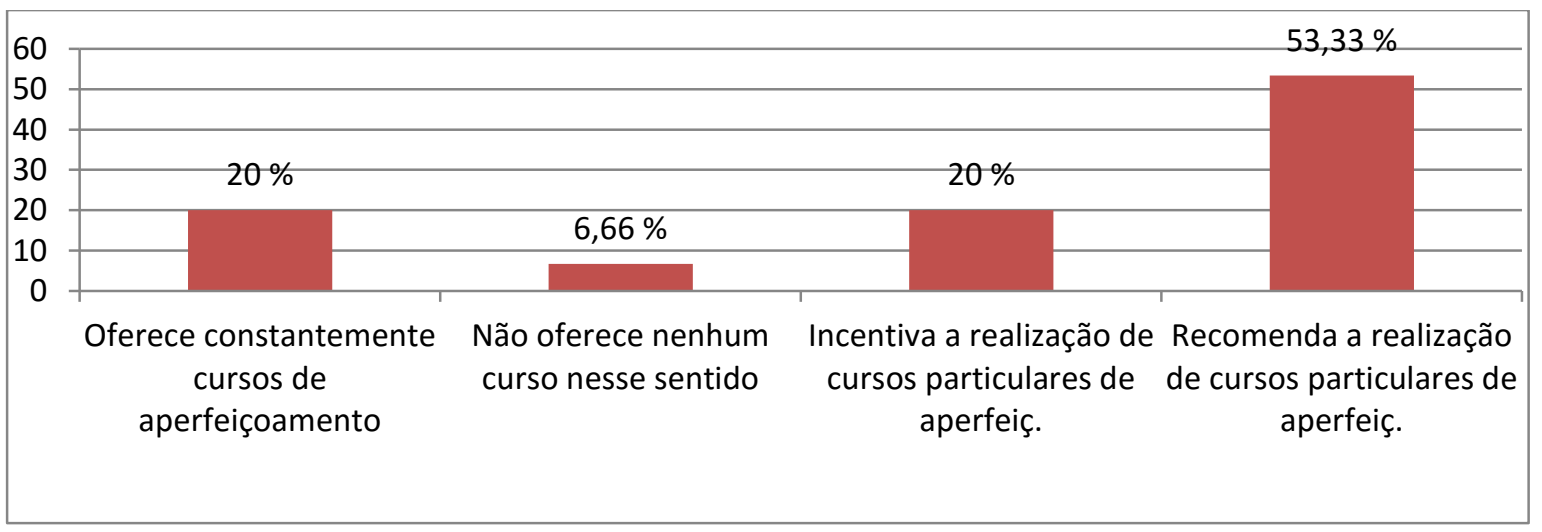

GRÁFICO 17 - Quanto ao uso das novas tecnologias, a unidade de informação,

Fonte: dados da pesquisa

Conforme informa o gráfico anterior, na percepção de 3 respondentes (20\%), a BU oferece constantemente cursos de aperfeiçoamento; contraditoriamente, 1 indivíduo afere que a unidade não oferece nenhum curso nesse sentido; já para 3 pessoas (20\%), a unidade incentiva os profissionais a realizarem cursos particulares de aperfeiçoamento; na visão da maioria, 8 pessoas $(53,33 \%)$ afirmam que a BU recomenda que os profissionais realizem cursos particulares de aperfeiçoamento.

É importante frisar que as unidades de informação, independente da categoria a que se inserem, diante da informatização dos serviços bibliotecários, devem incentivar os 
profissionais da informação a realizarem cursos de capacitação a fim de tornarem-se competentes a usar os recursos oferecidos pelo ambiente digital, pois, assim, inúmeras possibilidades de tratamento, armazenamento e recuperação da informação serão construídas tornando resolvidos inúmeros problemas acometidos pela acelerada explosão da informação.

\section{CONSIDERAÇÕES FINAIS}

A partir das reflexões propostas neste estudo, constata-se que os bibliotecários, visando adequar-se às novas ambiências de trabalho, devem ampliar suas competências, tornando-se envolvidos com questões que ultrapassem os tradicionais serviços técnicos voltados para o tratamento de acervos bibliográficos.

O surgimento da sociedade da informação, aliado aos novos recursos tecnológicos, transformaram as unidades de informação, sobretudo as BUs, devendo elas adequarem-se às múltiplas necessidades e preferências dos usuários, em meio a um ambiente híbrido, o que irá condicionar a necessidade de aperfeiçoamento dos usuários da informação e dos profissionais que estão à frente dos serviços de informação.

No contexto da BU, os bibliotecários devem adquirir o status de MIP, utilizando-se de diferenciadas competências a fim de tornarem-se preparados para atuar em meio a um ambiente mutante e diversificado. Ao adquirir novas competências, esse profissional pode atuar em vários setores, atendendo a diversidade e complexidade da BU.

A partir dessa contextualização, constata-se que o século XXI propicia o aparecimento de um novo bibliotecário, centrado a fazeres técnicos e humanistas, atuando de forma próativa e interdisciplinar em atividades que requerem comunicabilidade, técnica, ciência, gestão e engajamento social.

Analisando os dados coletados no estudo em uma BU, pode-se inferir, em linhas gerais, que o trabalho desenvolvido nessa modalidade de biblioteca é árduo, condicionando o bibliotecário a buscar formação continuada a fim de tornar-se capacitado a exercer atividades inovadoras. Fica evidenciado que o bibliotecário deve adquirir competências específicas, tais como: comunicação/expressão, técnica-científica, gerenciais e sociais e políticas, tornando-se um profissional multifuncional, integrado, criativo e polivalente.

O estudo demonstra que a BU investigada reconhece a ampliação dos fazeres biblioteconômicos, viabilizando esforços no sentido de motivar e favorecer a adequação do bibliotecário ao status de MIP, sendo necessário para isso o engajamento com a formação continuada do profissional.

Pelas análises realizadas, percebe-se que as competências exigidas para que o bibliotecário seja MIP no contexto da BU somente se efetivam se houver, primeiramente, interesse por parte do profissional e, aliado a esse fato, a própria BU incentivar os profissionais a buscar novas formas de capacitação. 
De modo geral, o estudo confirma que as competências do MIP são praticadas pelos bibliotecários que atuam em $\mathrm{BU}$, sendo necessário, a priori, o investimento na formação continuada. Essa formação é praticada pelos profissionais de diferentes formas, sendo também viabilizada pela unidade de informação, cabendo ao próprio profissional divulgar essa necessidade e desejo constante de aprimoramento, com vistas a consolidar a melhoria contínua dos serviços prestados nessas unidades de informação.

O estudo viabiliza a necessidade de realização de novas pesquisas, focada no usuário, no intento de perceber seus anseios diante das novas características híbridas existentes na ambiência atual da BU. Devido à análise delimitada deste estudo, voltada exclusivamente para as competências do bibliotecário, faz-se pertinente, a realização de outros estudos que demonstrem os esforços realizados pela BU para que a comunidade usuária adquira competências necessárias a utilizar com efetividade os serviços e produtos oferecidos na ambiência dessas unidades híbridas.

\section{REFERÊNCIAS}

BEM, Roberta Moraes de. NUEMBERG, Adriano Henrique; PEREIRA, Clarissa Agostini; RICHTER, Marivone. O papel da Biblioteca Universitária na vida acadêmica do estudante com deficiência: Ambiente de Acessibilidade Informacional da UFSC. In: AMBONI, Narcisa de Fátima (Org.). Gestão de bibliotecas universitárias: experiências e projetos da UFSC. Florianópolis: UFSC, 2013, p. 69-78.

CARVALHO, Maria Carmen Romcy de. Apresentação. In: Nídia, Lubisco. Biblioteca universitária: elementos para o planejamento, avaliação e gestão. Salvador: EDUFBA, 2011, p. $9-10$.

CASTRO, César Augusto. Profissional da informação: perfis e atitudes desejadas. Inf. \& Soc.: Est., João Pessoa, v. 10, n. 1, 2000.

CUNHA, Murilo Bastos da. Construindo o futuro: a biblioteca universitária brasileira em 2010. Ci. Inf., Brasília, v. 29, n. 1, p. 71-89, jan./abr. 2000. Disponível em: < http://www.scielo.br/pdf/ci/v29n1/v29n1a8.pdf>. Acesso em: 15 abr. 2014.

A biblioteca universitária na encruzilhada. Data GramaZero. Revista de Ciência da Informação, v.11, n.6, dez./2010. Disponível em: <http://www.dgz.org.br/dez10/Art_07.htm>. Acesso em: 2 out. 2013.

FEDERAÇÃO INTERNACIONAL DE BIBLIOTECÁRIOS (IFLA). Manifesto para as bibliotecas digitais. 2013. Disponível em: $<$ http://biblioo.info/ vwpcontent/uploads/2012/11/Manifesto-IFLA.pdf>. Acesso em: 3 out. 2013.

GARCEZ, Eliane Maria Stuart; RADOS, Gregório J. Varvakis. Biblioteca híbrida: um novo enfoque no suporte à educação a distância. Ci. Inf., Brasília, v. 31, n. 2, p. 44-51, maio/ago. 2002. Diponível em: 〈http://www.scielo.br/pdf/ci/v31n2/12907.pdf >. Acesso em: 21 fev. 2013. 
GUIMARÃES, José Augusto Chaves. Moderno Profissional da Informação: elementos para sua formação no Brasil. Transinformação, Campinas, v. 9, n. 1, p. 124-137, 1997.

LUBISCO, Nidia. O seminário avaliação da biblioteca Universitária brasileira: contexto, dinâmica e resultados. In: (Org.). Biblioteca universitária: elementos para o planejamento, avaliação e gestão. Salvador: EDUFBA, 2011, p. 17-43.

MARCHIORI, Patrícia Zeni. Eram os deuses astronautas? Ou são os bibliotecários profissionais da informação? São Paulo: APB, 1996.

MILANO, Manoelle Cristine Dalri; DAVOK, Delsi Fries. Consultor de informação: serviços prestados Por empresas de consultoria nas áreas de Biblioteconomia e gestão da informação. Revista ACB, Florianópolis, v.14, n.1, p.253-278, jan./jun., 2009. Disponível em: <http://revista.acbsc.org.br/racb/article/view/658/726>. Acesso em: 27 mar. 2014.

MIRANDA, Antônio Carlos. Desenvolvimento de coleções em Bibliotecas universitárias. Revista de Biblioteconomia e Ciência da Informação, Campinas, v. 4, n. 2, p. 01-19, jan./jun. 2007.

PONJUÁN DANTE, Glória. Perfi 1 del profesional de información del nuevo milenio. In: VALENTIM, Marta Lígia (Org.). Profissionais da informação: formação, perfil e atuação profissional. São Paulo: Polis, 2000, p.91-105.

SANTA ANNA, Jorge. (Re)pensando o fazer bibliotecário: da posse informacional ao acesso. In: SEMINÁRIO DE INFORMAÇÃO EM ARTES, 3. Rio de Janeiro: REDARTE, 2013, 01 CD.

SANTA ANNA, Jorge; PEREIRA, Gleice; CAMPOS, Suelen de Oliveira. Sociedade da Informação x Biblioteconomia: em busca do Moderno Profissional da Informação (MIP). In: SEMINÁRIO DE INFORMAÇÃO EM ARTES, 3. Rio de Janeiro: REDARTE, 2013, 01 CD.

SANTA ANNA, Jorge; GERLIN, Meri Nadia; SIQUEIRA, Poliana. A tecnologia da informação e seus reflexos no serviço de referência da Biblioteca Central da UFES. In: CONGRESSO BRASILEIRO DE BIBLIOTECONOMIA, DOCUMENTAÇÃO E CIÊNCIA DA INFORMAÇÃO, 25., 2013, Florianópolis. Anais eletrônicos... Florianópolis: FEBAB, 2013. p. 1-14. Disponível em: <http://portal.febab.org.br/anais/article/view/1373>. Acesso em: 2 out. 2013

SILVEIRA, Fabrício José Nascimento da. O bibliotecário como agente histórico: do "humanista" ao "Moderno Profissional da Informação. Inf. \& Soc., João Pessoa, v. 18, n.3, p. 83-94, set./dez. 2008. Disponível em: <http://www.ies.ufpb.br/ojs/index.php/ies/article/view/1873/2275>. Acesso em: 2 out. 2013.

SMIT, Johanna W. O profi ssional da informação e sua relação com as áreas de Biblioteconomia/Documentação, Arquivologia e Museologia. In: VALENTIM, Marta Lígia (Org.). Profissionais da informação: formação, perfil e atuação profissional. São Paulo: Polis, 2000, p.119-134. 
TAMMARO, Anna Maria; SALARELLI, Alberto. A biblioteca digital. Brasília: Briquet de Lemos, 2008.

TARAPANOFF, Kira. Perfil do profissional da informação no Brasil: diagnósticos de necessidades de treinamento e educação continuada. Brasília: Instituto Euvado Lodi, 1997.

VALENTIM, Marta Lígia Pomin. O moderno profissional da informação: formação e perspectiva profissional. Encontros Bibli: Revista de Biblioteconomia e Ciência da Informação. Florianópolis, n.9, p.16-27, jun. 2000.

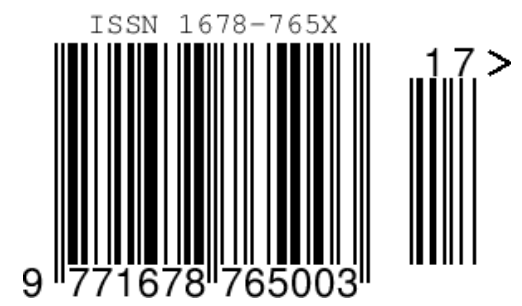

SANTA ANNA, Jorge; CALMON, Maria Aparecida de Mesquita. O bibliotecário atuante em bibliotecas universitárias no Século XXI: A necessidade de adequação ao moderno profissional da informação (MIP). RDBCl: Revista Digital de Biblioteconomia e Ciência da Informação, Campinas, SP, v. 14, n. 1, p. 49-67, dez. 2015. ISSN 1678-765X. Disponível em: $<$ http://periodicos.sbu.unicamp.br/ojs/index.php/rdbci/article/view/2127/9516 > . Acesso em: 01 fev. 2016. doi:http://dx.doi.org/10.20396/rdbci.v14i1.2127. 